\title{
Differential Transcript Profiles of MHC Class Ib (Qa-1, Qa-2, and Qa-10) and Aire Genes during the Ontogeny of Thymus and Other Tissues
}

\author{
Breno Luiz Melo-Lima, ${ }^{1,2,3}$ Adriane Feijó Evangelista, ${ }^{4}$ \\ Danielle Aparecida Rosa de Magalhães, ${ }^{4}$ Geraldo Aleixo Passos, ${ }^{4}$ \\ Philippe Moreau, ${ }^{2,3}$ and Eduardo Antonio Donadi ${ }^{1}$ \\ ${ }^{1}$ Basic and Applied Immunology Program, Division of Clinical Immunology, Department of Medicine, \\ Faculty of Medicine of Ribeirão Preto, University of São Paulo, Avenida Bandeirantes 3900, 14049-900 Ribeirão Preto, SP, Brazil \\ ${ }^{2}$ Commissariat à l'Energie Atomique et aux Energies Alternatives, Institut des Maladies Emergentes et des Therapies Innovantes, \\ Service de Recherches en Hémato-Immunologie, Hôpital Saint-Louis, 1 avenue Claude Vellefaux, Bâtiment Lailler, \\ 75475 Paris Cedex 10, France \\ ${ }^{3}$ Université Paris-Diderot, Sorbonne Paris-Cité, UMR E5, Institut Universitaire d'Hématologie, Hôpital Saint-Louis, \\ 1 avenue Claude Vellefaux, 75475 Paris Cedex 10, France \\ ${ }^{4}$ Molecular Immunogenetics Group, Department of Genetics, Faculty of Medicine of Ribeirão Preto, University of São Paulo, Avenida \\ Bandeirantes 3900, 14049-900 Ribeirão Preto, SP, Brazil
}

Correspondence should be addressed to Breno Luiz Melo-Lima; brenol@usp.br

Received 8 January 2014; Accepted 7 March 2014; Published 16 April 2014

Academic Editor: Enrico Fainardi

Copyright (C) 2014 Breno Luiz Melo-Lima et al. This is an open access article distributed under the Creative Commons Attribution License, which permits unrestricted use, distribution, and reproduction in any medium, provided the original work is properly cited.

Qa-2 and Qa-1 are murine nonclassical MHC class I molecules involved in the modulation of immune responses by interacting with $\mathrm{T} \mathrm{CD}^{+}$and NK cell inhibitory receptors. During thymic education, the Aire gene imposes the expression of thousands of tissue-related antigens in the thymic medulla, permitting the negative selection events. Aiming to characterize the transcriptional profiles of nonclassical MHC class I genes in spatial-temporal association with the Aire expression, we evaluated the gene expression of H2-Q7(Qa-2), H2-T23(Qa-1), H2-Q10(Qa-10), and Aire during fetal and postnatal development of thymus and other tissues. In the thymus, H2-Q7(Qa-2) transcripts were detected at high levels throughout development and were positively correlated with Aire expression during fetal ages. H2-Q7(Qa-2) and H2-T23(Qa-1) showed distinct expression patterns with gradual increasing levels according to age in most tissues analyzed. H2-Q10(Qa-10) was preferentially expressed by the liver. The Aire transcriptional profile showed increased levels during the fetal period and was detectable in postnatal ages in the thymus. Overall, nonclassical MHC class I genes started to be expressed early during the ontogeny. Their levels varied according to age, tissue, and mouse strain analyzed. This differential expression may contribute to the distinct patterns of mouse susceptibility/resistance to infectious and noninfectious disorders.

\section{Introduction}

Immune tolerance has been assigned to two broad categories according to the places where it occurs, that is, central and peripheral tolerance [1]. It is well known that nonclassical Major Histocompatibility Complex class I molecules (MHC Ib), like HLA-G and HLA-E, are associated with the regulation of immune responses in the periphery; however, little is known regarding the effect of these molecules at the central level. Human MHC Ib molecules exhibit restricted tissue distribution and do not have an important role in antigen presentation, and the coding regions of the respective genes have relatively low variability, particularly at exons that code major functional regions of the molecules [2].

In mice, two molecules have been described to be functional homologues of HLA-G and HLA-E: Qa-2 and 
Qa-1, respectively. Like humans, Qa-2 and Qa-1 molecules are involved in the regulation of immune responses and are encoded by the H2-Q7/H2-Q9 (also called PED genepreimplantation embryo development gene) and H2-T23 genes, respectively, both located in Histocompatibility Complex-2 (H-2) [3, 4].

The $\mathrm{H}-2$ spans approximately $4 \mathrm{Mb}$ of chromosome 17 (23.0 cM, cytoband B-C) and contains 3 major classes of highly polymorphic gene sets: class I $(\mathrm{H}-2-\mathrm{K}, \mathrm{H}-2-\mathrm{D}, \mathrm{Q}$, and $\mathrm{H}$-2-T18 genes), class II ( $\mathrm{H}-2-\mathrm{I}$ genes), and class III $(\mathrm{H}-2-\mathrm{S}$ genes). These genes are involved in many immunological processes, including graft rejection, immune response, antigen presentation, and complement component [5]. The number of class I genes, their organization, structural characteristics, and their patterns and levels of expression differ from species to species [3]. In general, $\mathrm{C} 57 \mathrm{BL} / 6$ and $\mathrm{BALB} / \mathrm{c}$ mice are considered in two different haplotypes: $H-2^{\mathrm{b}}$ and $H-2^{\mathrm{d}}$, respectively [4] (http://www.informatics.jax.org/).

The murine Qa-2 genes map to the $\mathrm{H}-2 \mathrm{Q}$ region, between the classical class I H-2D locus and the H-2TL cluster of class $\mathrm{lb}$ sequences. This locus encodes a variable number of class Ib genes in different strains [3]. Strains expressing high (Qa-2 $\left.{ }^{\text {high }}\right)$, medium $\left(\mathrm{Qa}-2^{\text {med }}\right)$, low $\left(\mathrm{Qa}-2^{\text {low }}\right)$, and no Qa$2\left(\mathrm{Qa}-2^{\text {nul }}\right)$ were identified [3]. In general, BALB/c strain is considered to be Qa-2 ${ }^{\text {med }}$ having two Qa-2 genes $\left(\mathrm{Q}^{\mathrm{d}}{ }^{\mathrm{a}}\right.$ and $\mathrm{Q}^{\mathrm{d}}$ ). In C57BL/10, considered to be Qa-2 ${ }^{\text {high }}$, four genes with the $\mathrm{Q} a-2$-coding properties are located within the $\mathrm{Q}$ regions: $\mathrm{Q}^{\mathrm{b}}, \mathrm{Q7}^{\mathrm{b}}$, and, additionally, Q8 ${ }^{\mathrm{b}}$ and $\mathrm{Q9}^{\mathrm{b}}$ [3].

Qa-2 is a $40-\mathrm{kDa}$ glycoprotein found as membranebound and soluble isoforms generated by alternative splicing $[3,6,7]$. Qa-2 is expressed mostly by lymphoid-derived cells and plays an important role in controlling growth and murine fetal development and, like HLA-G, the molecule is related to the protection of the fetus by inhibiting maternal NK cellmediated lysis [8-10].

Qa-1 is a $48 \mathrm{kDa}$ cell surface glycoprotein currently found in association with $\beta 2$-microglobulin $[4,11]$. Its surface expression is found in lower levels virtually in all tissues and is increased in activated hematopoietic, T, B, and antigens presenting cells [4]. Qa-1 is involved in suppression of $\mathrm{CD}^{+} \mathrm{T}$ cell and NK cell responses through a preferential interaction with inhibitory CD94/NKG2A receptors $[4,12]$. The suppression and modulation of autoreactive $\mathrm{T} \mathrm{CD} 4^{+}$ and $\mathrm{B}$ clones is mediated by $\mathrm{T} \mathrm{CD}^{+}$regulatory cells that recognize autoantigens presented by Qa-1 molecules $[4,12$, 13]. These regulatory cells perform perforin-mediated lysis and production of immunomodulatory cytokines such as TGF- $\beta$ and IL-10 $[4,12,13]$.

Another murine MHC class Ib molecule involved in the modulation of the immune system is Qa-10, encoded by the H2-Q10 gene. Qa-10 is synthesized at high levels by the liver parenchymal cells and is easily detectable in the serum as a high multivalent complex [14]. It has been suggested that Qa10 liver cell expression may be responsible for the relative lack of immunogenicity of liver transplants and better acceptance of liver allografts $[15,16]$.

It has been postulated that the regulatory role played by MHC class Ib molecules is an additional mechanism that controls autoimmune reactions in peripheral autoreactive lymphocytes that escaped from central tolerance during the ontogeny of the thymus [13]. Indeed, the mechanisms of central tolerance that occur during thymus development are critical processes for the prevention of autoimmunity during the fetal and neonatal periods $[17,18]$. This process characterizes the negative selection that purges the $\mathrm{T}$ cell repertoire of self-reactive clones through clonal deletion, inactivation, or deviation $[18,19]$. The medullary thymic epithelial cells (mTECs) are primarily associated with negative selection through the expression of a wide array of tissue-restricted antigens (TRAs), a process also termed promiscuous gene expression (PGE) [20-22].

PGE is greatly dependent on the Aire gene (autoimmune regulator) [18, 21]. A mutation in this gene leads to a severe multiorgan autoimmune polyglandular syndrome type I (APS 1, also called APECED), in both mice and humans $[17,18]$. It has currently been reported that most genes encoding promiscuously expressed TRAs in the thymus are regulated by a single Aire gene product, which is involved in a multiprotein complex transcriptional process responsible for transcription initiation, modifications of chromatin, transcriptional regulation of mRNA during the productive elongation phase, and regulation of alternative splicing events of the pre-mRNA $[23,24]$.

Interestingly, the expression of several MHC class Ib molecules has been reported on certain thymic cell subpopulations in mice and humans. Qa-2 expression has been used to identify functionally competent medullary thymocytes [2527]. HLA-G is highly expressed on mTECs and stromal cells at the corticomedullary junction, and high levels of soluble HLA-G are observed in the thymus medullary compartment [28]. Qa-1 is expressed on the surface of hematopoietic cells responsible for the positive selection of Qa1-restricted $\mathrm{CD}^{+}$ $\mathrm{T}$ cells, allowing the maturation and selection of potentially self-reactive $\mathrm{T} \mathrm{CD}^{+}$regulatory cells $[4,11]$. In addition to expressing immunoregulatory MHC Ib molecules, the thymus is the primary site of Aire expression, which is characteristically synthesized by mTEC subsets, intrathymic dendritic cells, and thymic macrophages [18].

During thymus ontogeny in the fetal stage, the expression of MHC class I and class II molecules is crucial for the education and selection of the repertoire of lymphocytes [29]. The early fetal thymus from E13.5 to E17.5 day p.c. is primarily composed of a homogeneous population of doublenegative $(\mathrm{DN}) \mathrm{CD}^{-} / \mathrm{CD}^{-}$precursor $\mathrm{T}$ cells. The gradual acquisition of the CD4 antigen occurs around E18.5 day, with the positive selection process starting thereafter [30]. This period (E16.5-E18.5) coincides with the onset of $\mathrm{V}(\mathrm{D}) \mathrm{J}$ recombination of $\mathrm{T}$ cell receptor in DN thymocytes and with the beginning of promiscuous gene expression, in which the Aire gene has a well-recognized role [31]. From the E18.5 day p.c., thymocytes gradually gain the phenotypic markers resembling the $\mathrm{T} \mathrm{CD} 4^{\text {low }}$ lymphocyte precursors in adults. These events allow the recognition and interaction of the $\mathrm{T}$ cell receptor with the MHC-peptide complex, allowing the occurrence of positive and negative selection in these cells [30]. The negative selection process occurs during perinatal 
ages and extends during the first 15 days after birth [17, 32]. This period is a critical stage in thymus ontogeny that is related to the mechanisms operating in the prevention of autoimmune processes [17, 32].

Considering that (i) many immunomodulatory MHC class Ib molecules are expressed in the thymus, (ii) Aire is a paradigmatic thymic immunomodulatory molecule that may have the ability to induce the expression of other molecules involved in the regulation of immune responses; (iii) many immunomodulatory molecules have differential temporal expression during thymus ontogeny, and (iv) different experimental strains may show distinct profiles of immunoregulatory molecules, we hypothesized that nonclassical MHC class I gene expression, such as H2-Q7(Qa-2), H2-T23(Qa$1)$, and $H 2-Q 10(\mathrm{Qa}-10)$, could be temporally related to Aire expression, participating in the occurrence of the central tolerance process and extending through the postnatal thymus development. To achieve this goal, we assessed the pattern of Aire expression and also the expression of nonclassical MHC class I genes by evaluating the temporal transcript profiles of Qa1, Qa2, Qa10, and Aire in the thymus of C57BL/6 and BALB/c mice, starting from the embrionary (E14.5 days) period and continuing till adulthood (60 days). The temporal transcript profile of these genes was also evaluated in some lymphoid and nonlymphoid tissues (spleen, liver, and gut) and in immunologically privileged sites (brain and placenta) to correlate with thymus findings.

\section{Material and Methods}

2.1. Animals. $\mathrm{C} 57 \mathrm{BL} / 6$ and $\mathrm{BALB} / \mathrm{c}$ mice were bred in an isolated cage provided with $0.45 \mu \mathrm{m}$ pore size air filter. To obtain an accurate day of gestation, the presence of a post coitum vaginal plug observed at 7:00 am was considered to be day zero. Fetuses were surgically collected from the uterus, and p.c. age was confirmed according to the morphological characteristics of each developmental phase [32]. Tissue samples were obtained in triplicate from (i) fetuses aged E14.5, E15.5, E16.5, E17.5, E18.5, E19.5, and E20.5 days of gestation, (ii) newborns aged 1, 5, 10, and 15 days, and (iii) adults aged 45 and 60 days. For each age were used at least 3 different animals. For tissue harvesting all tissues were washed in saline solution and then processed. For thymus both lobes were processed. For spleen, liver, gut, placenta, and brain only the same portions of tissues were analyzed. There was no separation between hematopoietic cells and parenchyma. Experimental procedures followed ethical guidelines under strict guidance and approval from the University of São Paulo Ethics Committee for Animal Experimental Research (Protocol number 043/2009).

2.2. RNA Extraction. After tissue isolation, total RNA samples were obtained by maceration of each tissue in TRizol reagent using a Potter homogenizer according to the manufacturer's instructions (Invitrogen, Carlsbad, CA) and treated with DNAse (deoxyribonuclease I amplification grade, Invitrogen). RNA integrity was checked by the presence of the $28 \mathrm{~S}$ and $18 \mathrm{~S}$ bands in $1.5 \%$ agarose gel, and only protein-free, phenol-free, and undegraded RNA species were used, as determined by UV spectrophotometry.

2.3. Analysis of Expression by Real-Time PCR. Total RNA isolated from samples was reverse-transcribed to cDNA using the High Capacity cDNA Transcription Kit (Applied Biosystems, Foster City, CA), following the manufacturer's instructions. cDNA amplification was initially carried out in a total volume of $25 \mu \mathrm{L}$, corresponding to $500 \mathrm{ng}$ of the initial RNA.

We assessed the expression of the H2-Q7(Qa-2), H2T23(Qa-1), H2-Q10(Qa-10), and Aire genes by quantitative real-time PCR using TaqMan Probe-Based Gene Expression Analysis (Applied Biosystems) in a total volume of $10 \mu \mathrm{L}$ containing $75 \mathrm{ng}$ total RNA, $5 \mu \mathrm{L}$ TaqMan PCR Universal Master Mix (Applied Biosystems), and $0.5 \mu \mathrm{L}$ TaqMan Gene Expression Assays. An ABI System Sequence Detector 7500 (Applied Biosystems) was used with the following regimen of thermal cycling: stage $1-1$ cycle for 2 minutes at $50^{\circ} \mathrm{C}$; stage $2-1$ cycle for 10 minutes at $95^{\circ} \mathrm{C}$; stage $3-40$ cycles for 15 seconds at $95^{\circ} \mathrm{C}$, followed by the last cycle for 1 minute at $60^{\circ}$ and 25 seconds at $72^{\circ} \mathrm{C}$. Gene expression was normalized relatively to the TaqMan endogenous controls (Applied Biosystems), using glyceraldehyde-3-phosphate dehydrogenase and $\beta$-actin genes. The relative quantification of transcript levels at the different ages and tissues was performed by the comparative $2^{-\Delta \Delta \mathrm{Ct}}$ method for each different analysis using the $\Delta \mathrm{Ct}$ minimum as control sample. Each sample was tested in triplicate. The TaqMan Inventoried Assays and TaqMan Gene Expression Assay reference are listed as follows: H2-Q7: Mm00843895_m1; H2-Q10: Mm01275264_m1; H2-T23: Mm00439246_ml; Aire: Mm00477461_m1; GAPDH: 4352339E; ACTB: 4352341E.

Statistical analysis was performed using one-way ANOVA followed by the Bonferroni multiple comparison test for analysis of gene expression profiles in different tissue samples. To compare age-related tissue samples between lineages, we used the Student's $t$-test. The analyses involving several variables (type of tissue, age, and genes) were performed using the two-way ANOVA Bonferroni's multiple comparison test with the aid of the Graphpad Prism V.5 software (San Diego, CA, http://www.graphpad.com/prism/). The Pearson product-moment correlation coefficient was calculated using R software version 2.14 .0 (http://www.r-project .org/). $P<0.05, P<0.01$, and $P<0.001$ were considered statistically significant.

\section{Results}

3.1. Analysis of MHC Class Ib and Aire Transcripts in Different Tissues of C57BL/6 Mice. Aiming to discriminate the primary organ of gene expression, we first compared each individual's gene transcript levels among the different tissues analyzed. We found that the $\mathrm{H} 2-\mathrm{Q} 7$ transcripts were primarily observed in thymus, followed by spleen and liver at all ages, being higher in adult thymus compared with other tissues along at different ages $(P<0.01)$ (Figure 1(a)). The transcript levels of H2-T23 were homogeneously expressed among all tissues, showing higher levels only in liver at adult ages $(P<0.01)$ 


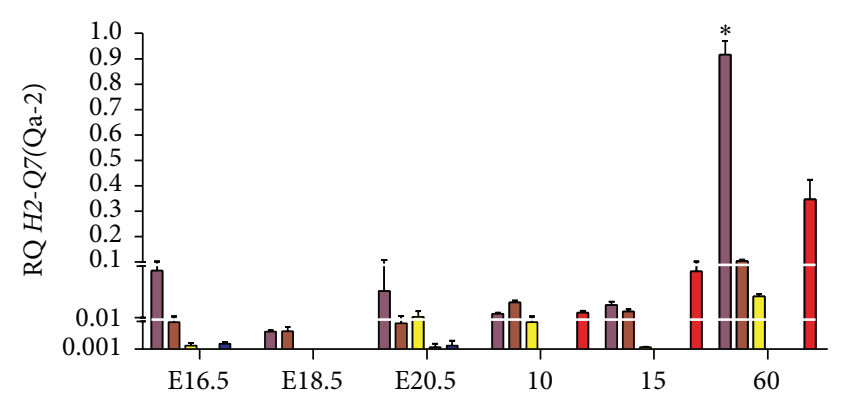

(a)

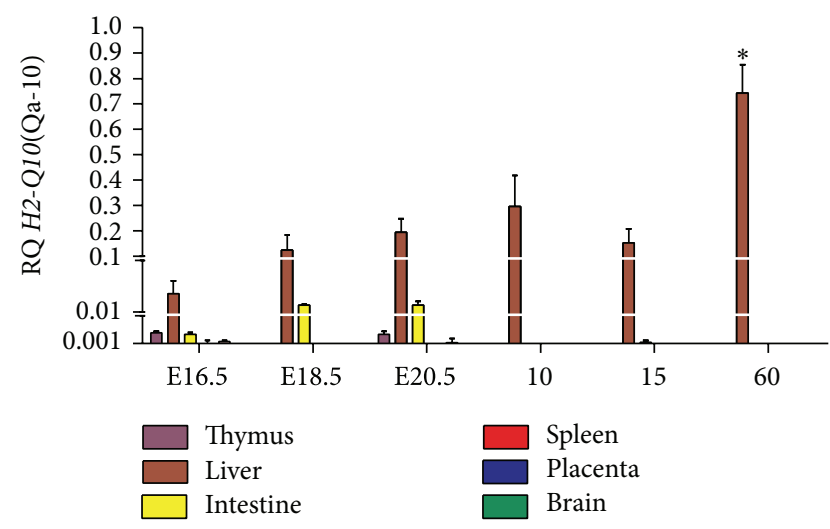

(c)

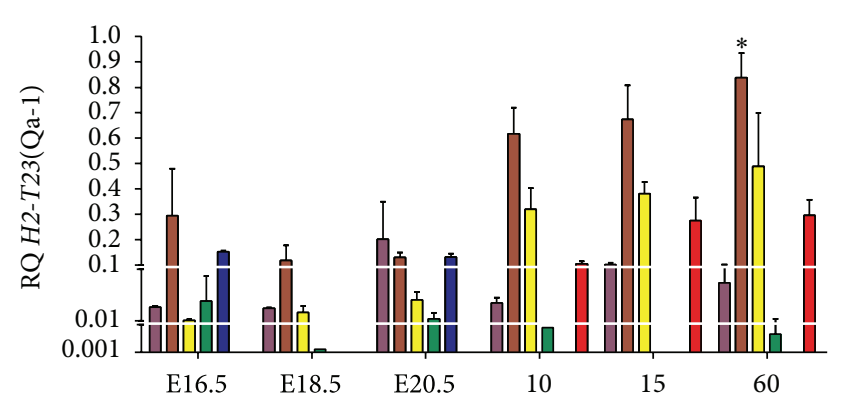

(b)

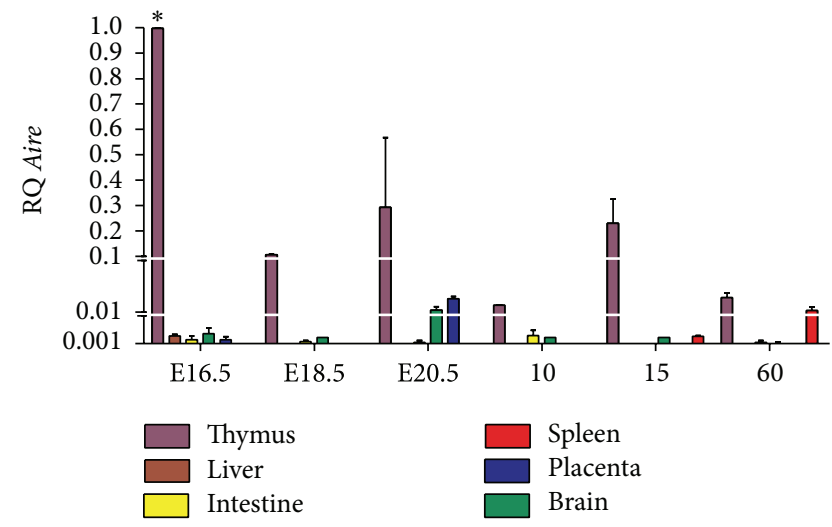

(d)

FIGURE 1: Analysis of MHC class Ib and Aire transcripts in different tissues of C57BL/6 mice. Relative quantification (RQ) of messenger RNA for (a) H2-Q7(Qa-2), (b) H2-T23(Qa-1), (c) H2-Q10(Qa-10), and (d) Aire is representative of the mean values of $2^{-\Delta \Delta C t}$. Tissue samples were obtained in triplicate from different animals for each age analyzed. Each experiment was independently performed at least three times. Data were analyzed statistically by two-way ANOVA followed by the Bonferroni multiple comparison test. Values close to the level of significance are marked with $(*)$.

(Figure 1(b)). H2-Q10 proved to be liver-specific, gradually increasing with age $(P<0.001)$. H2-Q10 expression was also detected in the fetal thymus and intestine (Figure 1(c)). Abundant levels of Aire transcripts were observed in the thymus during fetal ages, with a peak occurring at day E16.5 $(P<0.001)$, although, at reduced levels, Aire transcripts were observed at all postnatal ages. In addition, restricted levels of this gene were observed in brain and placenta (during fetal periods) and in spleen of adult mice (Figure $1(\mathrm{~d})$ ). In this analysis the gene transcript levels of each gene singly were compared between all tissues and ages.

3.2. Comparisons of Gene Expression Profiles of MHC Class $I b$ and Aire during Development of Thymus, Lymphoid, and Nonlymphoid Tissues in C57BL/6 Mice. To compare the transcription pattern during organ ontogeny, we analyzed each transcript in isolated tissues according to age. During fetal thymus development, both H2-Q7 and Aire transcripts were significantly increased at E16.5 days in comparison to H2-Q10 and H2-T23 at all ages $(P<0.001)$. In addition, H2-Q7 was the most widely expressed gene throughout the period of thymus development, reaching significance at E16.5, 45, and 60 days $(P<0.001)$. In adult thymus, Aire transcripts were observed at levels similar to H2-Q10 and H2-T23 (Figure 2(a)). In liver samples, H2-Q10 expression was high and increased with aging (Figure 2(b)); however, in gut samples, these transcripts were elevated during fetal and perinatal ages $(P<0.05)$. During postnatal periods, the H2-T23 gene was the most expressed $(P<0.001)$, followed by H2-Q7 $(P<0.01)$ (Figure $2(\mathrm{c}))$. In the spleen, a gradual transcript increase was observed for H2-Q7 and H2-T23. H2-Q7 was significantly higher in spleen samples from 60 -day-old animals $(P<0.001)$. A diminished expression of Aire was observed in spleen samples at postnatal ages (Figure 2(d)). Interestingly, during the evolution of pregnancy, the H2-T23 transcripts levels were higher than H2-Q7 at day E15.5 $(P<0.001)$ and day E16.5 $(P<0.001)$, and at day E20.5 $(P<0.05)$ in placenta samples (Figure 2(e)). Overall, MHC class Ib transcripts were observed at very restricted levels in brain at all ages analyzed, except for a faint expression of $H 2-Q 7$ transcripts during the perinatal period (Figure 2(f)).

3.3. Individual Transcript Patterns of H2-Q7(Qa-2), H2T23(Qa-1), H2-Q10(Qa-10), and Aire throughout Development in $C 57 B L / 6$ Mice. The individual values of the transcripts for H2-Q7, H2-Q10, H2-T23, and Aire throughout the development are shown in Table 1 and are representative of the mean values of $2^{-\Delta \Delta \mathrm{Ct}}$. 


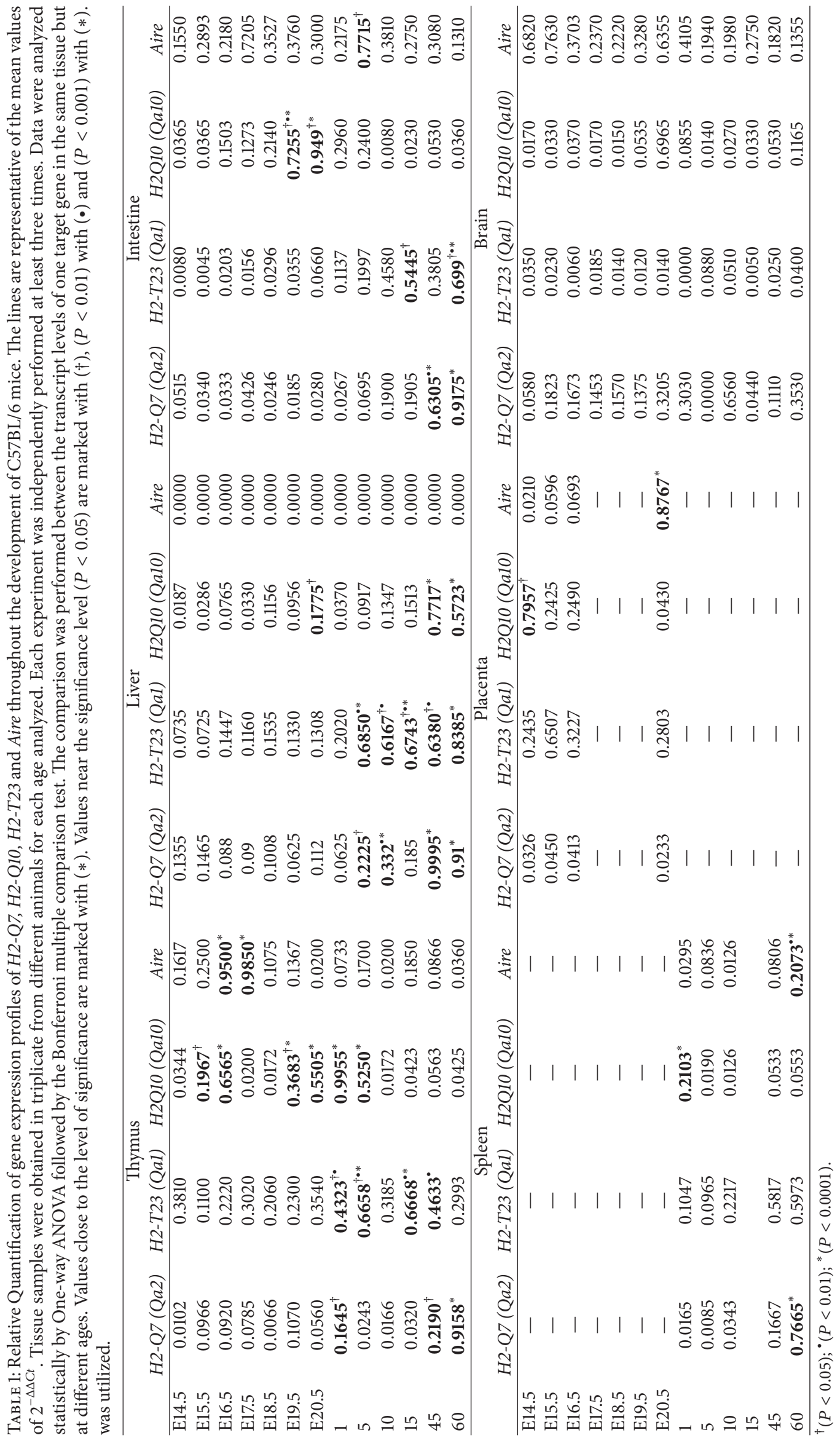




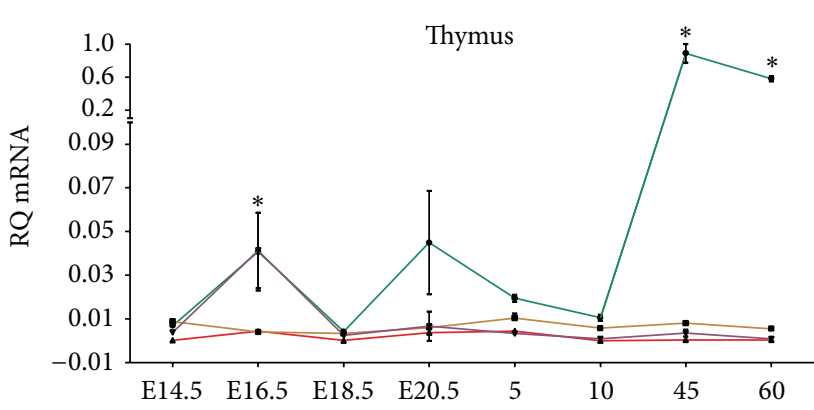

(a)

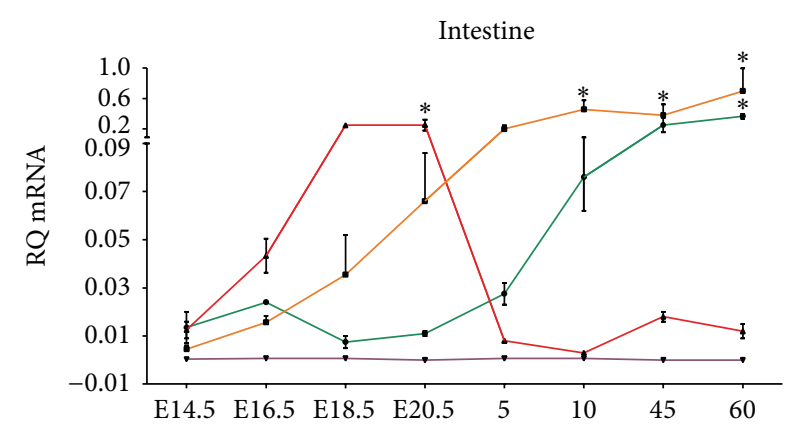

(c)

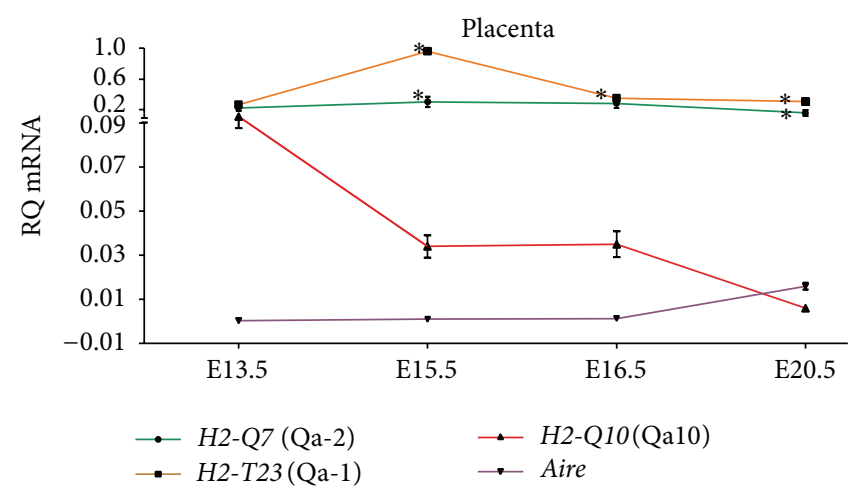

(e)

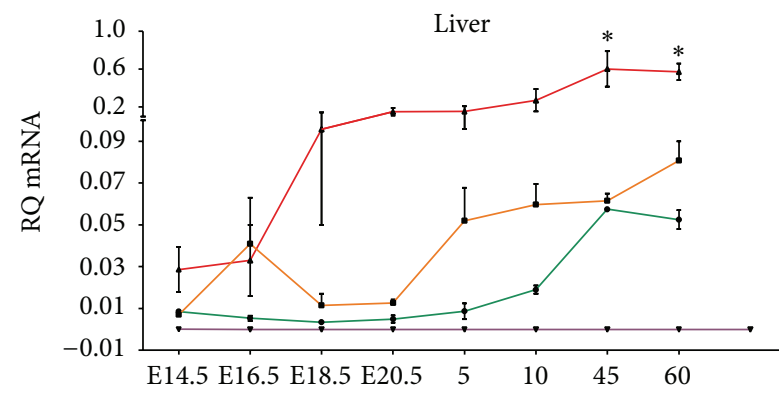

(b)

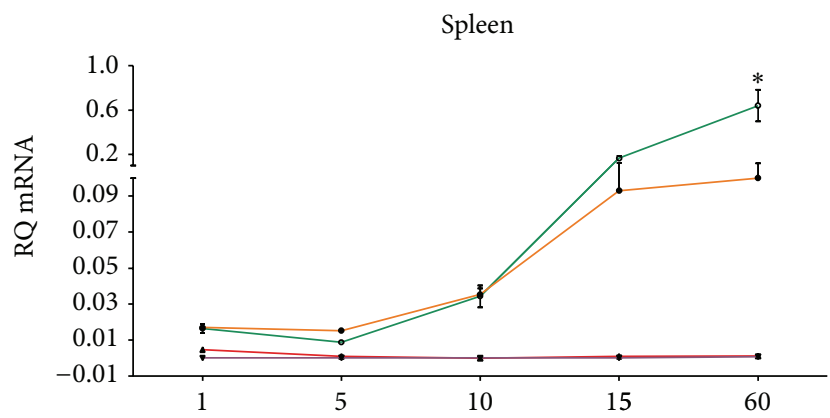

(d)

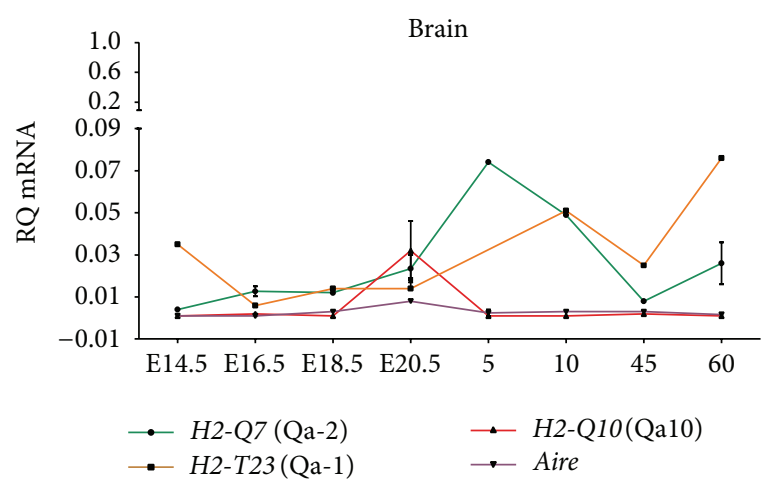

(f)

Figure 2: Comparisons of gene expression profiles of MHC class Ib and Aire during development of thymus, lymphoid, and nonlymphoid tissues in C57BL/6 mice. Relative quantification (RQ) obtained from (a) thymus, (b) liver, (c) intestine, (d) spleen, (e) placenta, and (f) brain is representative of the mean values of $2^{-\Delta \Delta \mathrm{Ct}}$. obtained from comparisons of the four genes in each tissue independently. Tissue samples were obtained in triplicate from different animals for each age analyzed. Each experiment was independently performed at least three times. Data were analyzed statistically by two-way ANOVA followed by the Bonferroni multiple comparison test. Values close to the level of significance are marked with $(*)$.

In the thymus, transcript levels of $H 2-Q 7$ gradually increased with age, reaching significance in mice aged 1,45 , and 60 days compared to other ages. H2-T23 expression was increased in animals aged $1,5,15$, and 45 days compared to fetal and adult ages. Although it is considered to be liver-specific, H2-Q10 expression was surprisingly increased during the fetal period of thymus development at days E15.5, E16.5, E19.5, and E20.5 and during the perinatal period at days 1 and 5. Aire expression was significantly increased during fetal thymus development, primarily at E16.5 and E17.5. Aire expression was maintained at reduced levels during postnatal periods in the thymus of newborn and adult animals.
In the liver, gene expression profiles of $H 2-Q 7$, H2-T23, and H2-Q10 were detected at low levels at fetal and perinatal ages, increasing after day 5. Postnatal expression of H2-Q7 and H2-Q10 peaked at days 45 and 60, whereas H2-T23 expression continued to be elevated from day 5 to 60. Aire gene transcription was not detected during liver development.

In the gut, the expression of H2-Q7 and H2-T23 was increased in the postnatal period, primarily from day 15 to day 60. In contrast, H2-Q10 transcripts peaked at late fetal periods on days E19.5 and E20.5. Aire expression was observed at all ages, exhibiting 


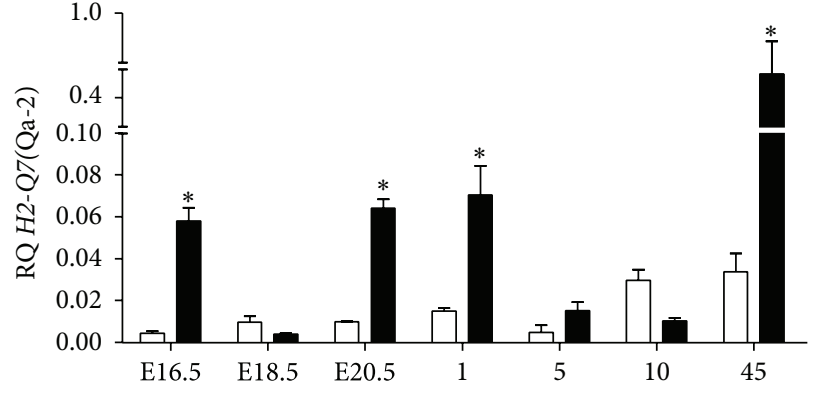

(a)

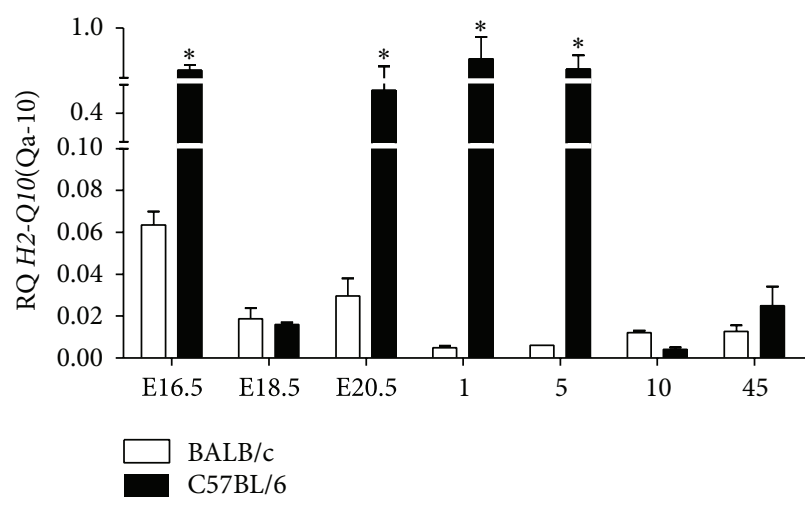

(c)

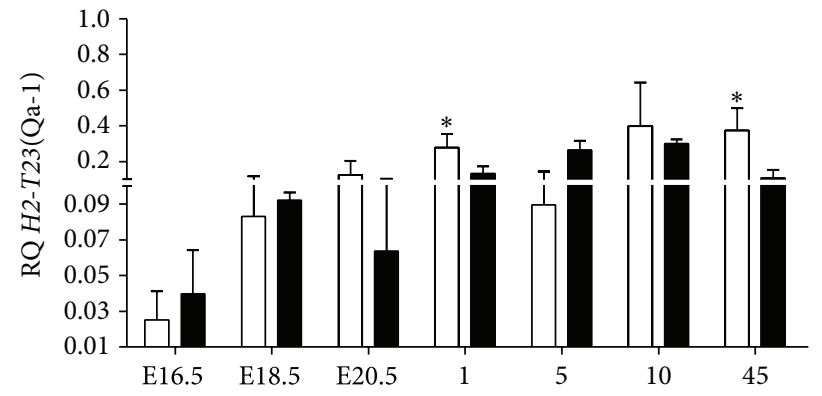

(b)

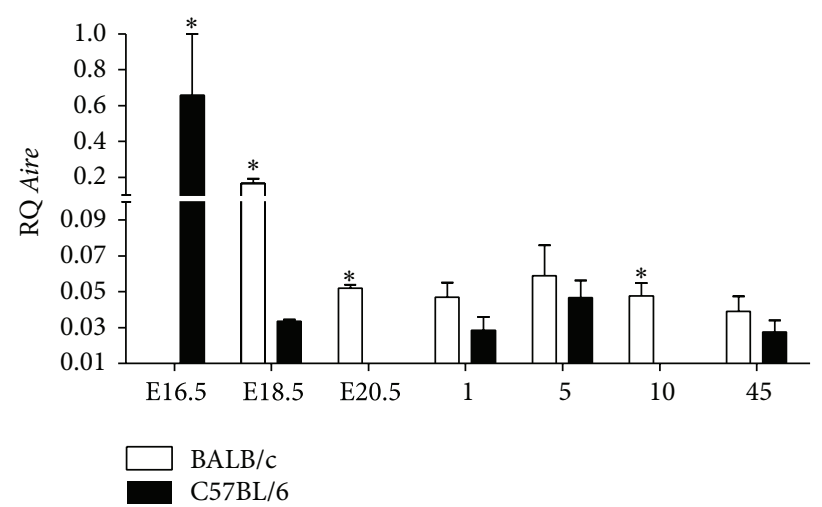

(d)

Figure 3: Comparison of gene expression profiles during thymus development between C57BL/6 and BALB/c mice. Relative quantification (RQ) of messenger RNA for (a) H2-Q7 (Qa-2), (b) H2-T23 (Qa-1), (c) H2-Q10 (Qa-10), and (d) Aire is representative of the mean values of $2^{-\Delta \Delta \mathrm{Ct}}$. Tissue samples were obtained in triplicate from different animals and lineages for each age analyzed. Each experiment was independently performed at least three times. Data were analyzed statistically by the Student's $t$-test. Values close to the level of significance are marked with $(*)$.

significant peak expression at day E14.5 and at perinatal day 5 .

Due to the late formation of the spleen, the tissue samples were obtained only during postnatal periods. H2-Q7 and Aire showed a closely similar expression pattern, exhibiting peak levels at day 60. In contrast, $H 2-Q 10$ transcripts peaked at day 1 . No significant differences in H2-T23 expression were observed.

In placenta samples, the gene expression profiles of $\mathrm{H} 2$ Q7 and H2-T23 showed no significant differences from day E14.5 to day E20.5. On the other hand, the expression of H2Q10 peaked at day E14.5 and the expression of Aire peaked at day E20.5.

In the brain, analysis of the expression of H2-Q7, H2T23, H2-Q10, and Aire in fetal and adult mice showed no significant differences.

3.4. Comparison of Gene Expression Profiles between C57BL/6 and $B A L B / c$ Mice. Compared with $B A L B / c$ mice, the C57BL/6 mouse thymus showed (i) higher transcript levels for H2-Q7 and H2-Q10 during fetal and postnatal development; (ii) increased levels of $\mathrm{H} 2-\mathrm{Q} 7$ on the following days: E16.5 $(P=0.0142)$, E20.5 $(P=0.0063), 1(P=0.0037)$, and $45(P<0.0001)$ (Figure $3(\mathrm{a}))$; (iii) closely similar $H 2$ T23 transcript levels, except at days 1 and 45, when H2-T23 expression levels were significantly increased in BALB/c mice ( $P=0.01$ and $P=0.0058$, resp.) (Figure 3(b)); (iv) increased levels of H2-Q10 mRNA in mice aged E16.5 $(P<0.01)$, E20.5 $(P<0.01), 1(P<0.001)$, and 5 postnatal days $(P<0.001)$ (Figure 3(c)); (v) a peak of Aire transcripts at day E16.5 $(P<0.001)$, while in BALB/c mice this peak occurred at day E18.5 of development $(P=0.0001)$. Overall, BALB/c mice expressed higher levels of Aire in the thymus at all other ages evaluated in this study, reaching significance at fetal E18.5 $(P=0.0001)$ and E20.5 days $(P=0.0318)$ and at 10 days after birth $(P=0.0004)$ (Figure $3(\mathrm{~d}))$.

Regarding other organs (liver, gut, spleen, placenta, and brain), C57BL/ 6 mice expressed considerably higher levels of H2-Q7 than BALB/c mice. In addition, H2-Q7 transcripts in fetal E17.5 liver $(P=0.0125)$, in E16.5 and E18.5 placentas $(P=0.00137)$, in 10 day spleen $(P=0.0146)$, and in 15-day gut $(P=0.0002)$ were higher in $\mathrm{C} 57 \mathrm{BL} / 6$ mice (data not shown). H2-T23 transcripts were more abundant in $\mathrm{BALB} / \mathrm{c}$ mice at most ages and in most organs compared to $\mathrm{C} 57 \mathrm{BL} / 6$ mice, being significantly increased at E17.5, E18.5, and E20.5 day in the fetal liver $(P=0.0057, P=0.0196$, and $P=0.0174$, resp.) and at day 10 in the gut $(P<0.001)$. No significant differences in H2-T23 levels were observed in the spleen of these mice (data not shown). H2-Q10 was significantly increased in fetal liver and fetal gut of C57BL/6 mice aged E20.5 $(P=0.0020)$ and E18.5 $(P=0.0210)$, 
respectively. C57BL/6 mouse placentas with E16.5 and E20.5 days of pregnancy $(P=0.0094$ and $P=0.018$, resp. $)$ showed augmented H2-Q10 levels. Overall, Aire transcripts were higher in BALB/c mice compared with $\mathrm{C} 57 \mathrm{BL} / 6$ mice, being significantly increased in 10 -day spleen $(P=0.0242)$, in E18.5, E20.5, and 15-day gut $(P=0.0002, P=0.0067$, and $P<0.01$, resp.), and in E20.5 day placenta $(P=0.0009)$ (data not shown).

3.5. Correlation of Gene Expression Profiles during Thymus Ontogeny. Considering the thymus tissue samples obtained at fetal ages, we found a positive correlation between Aire and H2-Q7 in both strains analyzed $(R=0.0378 / P=$ 0.4025 for $\mathrm{C} 57 \mathrm{BL} / 6$, and $R=0.03618174 / P=0.9638$ for BALB/c). Negative correlations between Aire and $\mathrm{H} 2$ T23 were found for C57BL/6 $(R=-0.0408 / P=0.9306)$ and for BALB $/ \mathrm{c}$ mice $(R=-0.1852341 / P=0.8148)$. In C57BL/6 mice, the expression of the H2-Q10 gene showed a positive correlation with Aire $(R=0.1311 / P=0.7793)$; however, a negative correlation was observed in BALB/c mice ( $R=-0.5067555 / 0.4932)$. After birth, negative correlations between Aire and H2-Q7 were observed for both strains $(R=-0.424 / P=0.4016$ for $\mathrm{C} 57 \mathrm{BL} / 6$, and $R=$ $-0.1140859 / P=0.8076$ for BALB/c). A positive correlation between Aire and H2-Q10 and Aire and H2-T23 was observed for $\mathrm{C} 57 \mathrm{BL} / 6$ and BALB/c mice $(R=0.3409015 / P=0.5085$ and $R=0.8148293 / P=0.04826$, resp.). However, in BALB/c mice this correlation was negative $(R=-0.4232537 / P=$ 0.3441 for $H 2-Q 10$, and $R=-0.1459941 / P=0.7548$ for $H 2-$ T23).

\section{Discussion}

4.1. MHC Class Ib Genes and the Thymic Selection. Although the Aire gene has a well-recognized role in central tolerance, the role of nonclassical MHC molecules, which also have tolerogenic properties, is not fully understood. To evaluate the relationship between Aire and nonclassical MHC class I genes, we studied the simultaneous expression of these genes during the ontogeny of lymphoid and nonlymphoid organs, from embryonic ages to adulthood.

In the present study, the H2-Q7 gene (Qa-2 molecule) was abundantly expressed in the thymus compared with other genes and in other tissues at any age analyzed. Several lines of evidence indicate that Qa-2 may be involved in migration, maturation, and effector mechanisms of cells that emigrate from the thymus. Cells exhibiting a high expression of Qa2 do migrate to the periphery and perform their effector mechanisms $[26,27]$, corroborating previous results showing that Qa-2 is a marker of medullary thymocytes in the final stages of development [25-27]. In addition, Qa-2 may be involved in the generation of $\mathrm{T} \mathrm{CD}^{+}$lymphocytes specific for antigens that are presented at the periphery in the context of these molecules $[12,26]$ and in the selection and regulation of CD $8 \alpha \alpha / \mathrm{TCR} \alpha \beta$ intraepithelial T cells [34].

In humans, the expression of HLA-G in the fetal thymus may be related to the inhibition of thymus NK cells, potentially capable of destroying thymocytes expressing classical
HLA class I molecules at low density [35] or even inducing apoptosis of $\mathrm{CD}^{+} \mathrm{T}$ cells via Fas expression $[8,28]$. Also, the expression of HLA-G by mTECs may induce immune tolerance driven by antigen-specific $\mathrm{T}$ cells through the expansion of natural regulatory $\mathrm{CD} 4^{+}$Foxp $^{+} \mathrm{T}$ cells $[8,36]$. Taken together, these findings indicate that the high expression of H2-Q7 during perinatal and adult ages may be related to the formation of subtypes of functionally mature thymocytes residing in thymic medulla. The increased expression of $\mathrm{H2}$ Q7 in adulthood may further indicate that, instead of thymic involution, the presence of mature and functional thymocytes may maintain the functionality of the thymus in thymocyte generation.

It is interesting to observe that the expression of the H2-Q7 and Aire genes exhibited closely similar profiles and showed positive significant correlations in C57BL/6 and in $\mathrm{BALB} / \mathrm{c}$ mice only during fetal ages. Negative selection is crucial to maintain the homeostasis of the immune system, a process in which the Aire gene plays a central role, since it is directly implicated in the control of the expression of thousands of TRAs $[21,22]$. Based on the positive correlations between the transcript profiles of Aire, H2-Q7, and H2-Q10 in the fetal thymus, we may hypothesize that nonclassical $\mathrm{MHC}$ class I genes are also under the transcriptional control of Aire. Additionally, it has been proposed that Aire may activate genes that are usually silenced or expressed at low levels due to methylation marks ( $\mathrm{H} 3 \mathrm{~K} 4 \mathrm{me} 0)$ in their promoter regions. The low expression and the presence of methylation marks may be a feature of Aire-dependent activation of genes which are not normally expressed, as in mTECs $[23,24]$. In humans, the expression of the $H L A-G$ gene is regulated at epigenetic levels due to the presence of methylation of $\mathrm{CpG}$ motifs in the promoter region $[37,38]$ and could also be under the transcriptional regulation of Aire.

In contrast to $\mathrm{H} 2-\mathrm{Q} 7$, we found a negative correlation between Aire and H2-T23(Qa-1) expression during fetal thymic development in both mouse strains. Indeed, H2-T23 transcription levels were reduced during the fetal period of thymus development, increasing during postnatal ages. These results corroborate previous studies reporting that Qa1 is primarily expressed by antigen-presenting cells and activated lymphocytes during the effector phase of the immune response $[4,11,12]$. The expression of Qa-1 (H2-T23) in the fetal thymus, as observed in the present study, may be related to the generation of regulatory T cells, since Qa-1 is involved in the regulation of autoimmunity by suppressive $\mathrm{CD}^{+} \mathrm{T}$ regulatory cells. The positive selection of potentially Qa-1-dependent CD8 ${ }^{+}$Tregs may allow the expansion of these regulatory cells in the peripheral lymphoid organs after encountering the cognate antigen $[4,11,12]$.

There are no previous studies evaluating the expression of H2-Q10 in the thymus, and there are few studies reporting the immunomodulatory role of the Qa-10 molecule. In this context, it has been reported that Qa-10 is liver-specific and may be related to better acceptance of hepatic allografts [14, 15]. At least at a transcriptional level, we demonstrated the expression of H2-Q10 outside the liver. Although a reduced expression of H2-Q10 during thymus ontogeny was observed in this study, the expression levels were higher during the fetal 
period. Additionally, we found a significant positive correlation between Aire and H2-Q10 in C57BL/6 mice both for embrionary and for postnatal ages. In contrast, we observed a significant negative correlation between Aire and H2-Q10 in $\mathrm{BALB} / \mathrm{c}$ mice for embrionary and postnatal ages. As proposed for H2-Q7, Aire may also be involved in the transcriptional regulation of $\mathrm{H2}-\mathrm{Q} 10(\mathrm{Qa}-10)$, which in turn may be involved in tolerance in the thymus. Since the expression patterns of Aire and H2-Q10 are distinct in different strains, one may hypothesize that H2-Q10 expression may be associated with differential immune response patterns, yielding differential susceptibility to foreign or modified self antigens.

\subsection{MHC Class Ib Genes during Ontogeny of Lymphoid and} Nonlymphoid Tissues. Overall, in peripheral organs such as the spleen, liver, and gut, the transcription profiles of $\mathrm{H} 2-\mathrm{Q} 7$, $H 2-Q 10$, and H2-T23 were characterized by a gradual increase of transcript levels with aging. In the spleen, the increased expression of H2-Q7 in C57BL/6 mice supports previous studies reporting that the expression of $\mathrm{Qa}-2$ by spleen cells is sufficiently high to prime $\mathrm{CD} 8^{+} \mathrm{T}$ cells [39]. Additionally, $\mathrm{H2}$ T23 transcripts found in this organ may be related to a higher state of activation of $\mathrm{T}$ cells, since the expression of Qa-1 preferentially occurs in activated immunocompetent cells [12].

In the liver, both during the fetal period and in adulthood, we observed an increased level of nonclassical MHC transcripts, particularly those encoding the Qa-10 molecule. The increased H2-Q10 liver transcription rates could serve to modulate immune responses maintaining the "immunosuppressed" state of the liver. This idea is corroborated by studies reporting that hepatocytes expressing Qa-10 are apparently free of autoimmune processes and show little evidence of cell damage [14]. The early expression of MHC class Ib genes may be involved in the maintenance of this "immunosuppressed" state from embryonic stage to adulthood. This maintained state of tolerance in liver cell subpopulations possibly contributes to the high rates of acceptance of liver transplants; however, it may also contribute to liver vulnerability to chronic pathogens, such as hepatitis viruses and Plasmodium spp. [40]. We agree with the idea raised by Stroynowski and Tabaczewski in which since Qa-10 appears in the circulation as a soluble molecule, the high expression of Qa-10 would be an additional mechanism by which the liver could impose systemic immunological tolerance, influencing the immune responses at other body sites, particularly in autoimmune manifestations or in allografts [3].

The transcription of the H2-Q7, H2-Q10, and H2-T23 genes was detected from E13.5 day during the embryonic development of liver. It is well established that during embryogenesis the fetal liver acts as an important hematopoietic organ, producing diverse cell types as the progenitors of $\mathrm{T}, \mathrm{B}, \mathrm{NK}$, and dendritic cells and monocytes $[41,42]$. Indeed, under normal conditions, these cells and hematopoietic stem cells are able to express Qa-2 and Qa-1 $[3,4]$. It has also been demonstrated that fetal liver mesenchymal stem cells express HLA-G molecules [43], and some subtypes of $\mathrm{CD} 8^{+}$ $\mathrm{T}$ cells have been identified as natural $\mathrm{CD} 8^{+} \mathrm{T}$ cells, exhibiting the $\mathrm{CD}^{+}{ }^{+} \mathrm{HLA}_{-} \mathrm{G}^{+}$and $\mathrm{CD} 8^{+} \mathrm{CD} 22^{+}$phenotypes [40].
Apparently, the expression of HLA-G in liver cells may contribute to immunosuppression events observed in the liver, favoring the chronification of infections $[44,45]$.

H2-Q7 expression in the gut is of potential interest, since several lines of evidence show that Qa-2 is involved in the selection and maintenance of mucosal CD $8 \alpha \alpha / \mathrm{TCR} \alpha \beta$ intraepithelial lymphocytes and therefore in the regulation of immune responses [39]. It is known that regulatory T cells are abundantly found in the lamina propria of the gut, which can be generated at these sites or may migrate through homing receptors to the gut [46]. Thus, the increased levels of H2T23 transcripts observed in the gut may be related to the involvement of Qa-1 in the suppression of NK cell responses and the maintenance and generation of $\mathrm{CD}^{+}$regulatory $\mathrm{T}$ cells, contributing to oral tolerance in the gut $[12,13]$.

The importance of Qa-1 and Qa-2 in the placenta was demonstrated by studies showing that $\gamma \delta$ TCR lymphocytes present in the decidua are oligoclonal and restricted to antigens presented by class Ib molecules. Interestingly, these populations of $\gamma \delta \mathrm{T}$ cells are selected in the thymus during the fetal period [47]. The expression profiles of H2-Q7 and H2T23 observed in our study are consistent with human studies showing that the HLA-G molecule has well-marked temporal regulation during pregnancy, with high expression in the first months and decreased expression in the third trimester of pregnancy [47]. Our observation that H2-T23 transcripts are more expressed $\mathrm{H} 2-\mathrm{Q} 7$ transcripts is surprising, considering that the placenta and embryonic tissues are described as the relevant sites of expression of Qa-2 and a major component of the H2-Q6/Q7/Q8/Q9 genes (Ped gene) involved in preimplantation and embryonic development $[6,9]$.

Overall, we did not observe expression of MHC class Ib genes in the brain, except for a faint expression of H2-Q7 and Aire transcripts in both mouse strains (data not shown). Under physiological conditions, brain Qa-2 expression has been associated with the development and plasticity of the organ [48]. On the other hand, in humans, induced brain expression of HLA-G has been reported during the course of inflammatory diseases such as multiple sclerosis and has been associated with inhibition of responses mediated by cytotoxic T cells, NK cells, and inhibition of T cell proliferation [46].

The expression of Aire transcripts outside the thymus, found here to be reduced in the brain and to occur in considerable levels in peripheral organs such as the spleen and gut, is quite interesting, since in recent years several studies have attempted to identify the expression of Aire and the occurrence of PGE in tissues other than the thymus $[17,18$, 32]. The relevance and functionality of the expression of Aire in peripheral lymphoid organs are still very controversial. Recently, it has been reported that the stromal cells of lymph nodes, spleen, and Peyer's patches express reduced levels of Aire. The expression of Aire by these organs occurs in certain eTACS (extra thymic Aire-expressing cells). In a similar way to mTECs, eTACS can perform promiscuous gene expression and are able to mediate deletion of autoreactive $T$ cells $[17,18]$.

4.3. Differential Transcript Profiles between Mice Strains. The comparisons of Aire gene expression profiles between strains 
corroborated our previous studies, showing a peak of Aire expression in C57BL/6 thymus at day E16.5 and in BALB/C thymus at day E18.5. Aire expression anticipated the PGE phenomenon in both strains and occurred after the beginning of TCR V(D)J recombination. This process starts on the E14.5 day and E16.5 day in C57BL/6 and BALB/c mice, respectively $[49,50]$. Therefore, the timing of $\mathrm{T}$ cell maturation during thymus development apparently differs between these strains, suggesting an important role of the genetic background in the modulation of these important thymus events [51, 52]. In addition, differences in imunomodulatory MHC class Ib gene expression profiles between strains, as observed in this study, may provide further evidence of the patterns of susceptibility and resistance to infections, autoimmune diseases, and cancers of these strains. In most age groups analyzed in this study, the expression of H2-Q7 in the thymus and other peripheral organs was significantly higher in $\mathrm{C} 57 \mathrm{BL} / 6$ mice than in $\mathrm{BALB} / \mathrm{c}$ mice. This may reflect the fact that BALB/c mice usually express lower levels of Qa-2 as they present a deletion of both H2-Q6 and H2-Q9 loci, and therefore the $\mathrm{BALB} / \mathrm{c}$ strain is characterized as medium producers of Qa-2 (Qa-2 $\left.{ }^{\text {med }}\right)$ [3].

Considering that $Q 7$ and $Q 9$ genes synergistically contribute to the expression of $\mathrm{Qa}-2$, the genetic differences between $\mathrm{BALB} / \mathrm{c}$ and $\mathrm{C} 57 \mathrm{BL} / 6$ mice may contribute to differential expression of Qa-2, which is approximately 4 to 5 times higher in C57BL/6 mice [3]. In contrast, H2-T23 and AIRE transcript levels were significantly higher in $\mathrm{BALB} / \mathrm{c}$ mice compared to C57BL/6 mice. Compared to C57BL/6 mice, $\mathrm{BALB} / \mathrm{c}$ mice are more vulnerable to infections triggered by Staphylococcus aureus, Mycoplasma pulmonis, and Leishmania major [51-53]. Considering that Qa-1 is clearly involved in the generation of regulatory T cells $[4,12,13]$ and that Aire may shape the repertoire of regulatory $T$ cells [18], increased expression of these transcripts may account for increased central regulatory function and increased susceptibility to infections [54].

\section{Conclusions}

The present study raised the idea of a potential transcriptional link between Aire and nonclassical MHC class I genes acting at a central level during thymic education and potentially influencing and modulating the immune responses at the periphery. Although using a generalist approach, this study aimed to characterize the transcription patterns of relevant immunomodulatory genes and may be useful for further studies regarding the involvement of nonclassical $\mathrm{MHC}$ class I molecules in immune tolerance events. The evaluation of the protein product encoded by these genes is crucial to understand the relationship and possible transcriptional regulation of nonclassical MHC class I molecules by Aire. Further analysis will be performed in this area in order to verify the potential influence of Aire on the promoter regions of H2-Q7, H2-Q10, and H2-T23. Studies involving appropriate animal models for MHC class Ib molecules can contribute to the current knowledge about HLA-G and HLA-E in humans and are a prerequisite for the development of therapeutic strategies such as the production of nonclassical MHC recombinants molecules associated with immunosuppressive therapy.

\section{Conflict of Interests}

The authors declare that there is no conflict of interests regarding the publication of this paper.

\section{Acknowledgments}

This work was supported by grants from the National Council for Scientific and Technological Development (CNPq) and by the binational collaborative CAPES/COFECB program (no. 653/09).

\section{References}

[1] J. D. Rioux and A. K. Abbas, "Paths to understanding the genetic basis of autoimmune disease," Nature, vol. 435, no. 7042, pp. 584-589, 2005.

[2] E. A. Donadi, E. C. Castelli, A. Arnaiz-Villena, M. Roger, D. Rey, and P. Moreau, "Implications of the polymorphism of HLA-G on its function, regulation, evolution and disease association," Cellular and Molecular Life Sciences, vol. 68, no. 3, pp. 369-395, 2011.

[3] I. Stroynowski and P. Tabaczewski, "Multiple products of class Ib Qa-2 genes which ones are functional?" Research in Immunology, vol. 147, no. 5, pp. 290-301, 1996.

[4] J. Klein, F. Figueroa, and C. S. David, "H-2 haplotypes, genes and antigens: second listing. II. The H-2 complex," Immunogenetics, vol. 17, no. 6, pp. 553-596, 1983.

[5] C. Amadou, A. Kumánovics, E. P. Jones, D. LambrachtWashington, M. Yoshino, and K. F. Lindahl, "The mouse major histocompatibility complex: some assembly required," Immunological Reviews, vol. 167, pp. 211-221, 1999.

[6] L. Wu, H. Feng, and C. M. Warner, "Identification of two major histocompatibility complex class Ib genes, Q7 and Q9, as the Ped gene in the mouse," Biology of Reproduction, vol. 60, no. 5, pp. 1114-1119, 1999.

[7] Z. Tian, Y. Xu, and C. M. Warner, "Removal of Qa-2 antigen alters the Ped gene phenotype of preimplantation mouse embryos," Biology of Reproduction, vol. 47, no. 2, pp. 271-276, 1992.

[8] E. D. Carosella, P. Moreau, J. LeMaoult, and N. Rouas-Freiss, "HLA-G: from biology to clinical benefits," Trends in Immunology, vol. 29, no. 3, pp. 125-132, 2008.

[9] M. Comiskey, C. Y. Goldstein, S. R. De Fazio, M. Mammolenti, J. A. Newmark, and C. M. Warner, "Evidence that HLA-G is the functional homolog of mouse Qa-2, the ped gene product," Human Immunology, vol. 64, no. 11, pp. 999-1004, 2003.

[10] P. J. Robinson, M. Millrain, J. Antoniou, E. Simpson, and A. L. Mellor, "A glycophospholipid anchor is required for Qa-2mediated T cell activation," Nature, vol. 342, no. 6245, pp. 85-87, 1989.

[11] E. Hermel, A. J. Hart, I. Gunduz et al., "Polymorphism and conservation of the genes encoding Qa1 molecules," Immunogenetics, vol. 56, no. 9, pp. 639-649, 2004.

[12] L. Lu and H. Cantor, "Generation and regulation of $\mathrm{CD}^{+}$ regulatory T cells," Cellular and Molecular Immunology, vol. 5, no. 6, pp. 401-406, 2008. 
[13] T. R. F. Smith and V. Kumar, "Revival of CD ${ }^{+}$Treg-mediated suppression," Trends in Immunology, vol. 29, no. 7, pp. 337-342, 2008.

[14] K. Wieties, R. E. Hammer, S. Jones-Youngblood, and J. Forman, "Peripheral tolerance in mice expressing a liver-specific class I molecule: inactivation/deletion of a T-cell subpopulation," Proceedings of the National Academy of Sciences of the United States of America, vol. 87, no. 17, pp. 6604-6608, 1990.

[15] A. M. Lew, W. L. Maloy, and J. E. Coligan, "Characteristics of the expression of the murine soluble class I molecule (Q10)," Journal of Immunology, vol. 136, no. 1, pp. 254-258, 1986.

[16] D. W. Mann, I. Stroynowski, L. Hood, and J. Forman, “Cytotoxic T lymphocytes from mice with soluble class I Q10 molecules in their serum are not tolerant to membrane-bound Q10," Journal of Immunology, vol. 138, no. 1, pp. 240-245, 1987.

[17] J. M. Gardner, A. L. Fletcher, M. S. Anderson, and S. J. Turley, "AIRE in the thymus and beyond," Current Opinion in Immunology, vol. 21, no. 6, pp. 582-589, 2009.

[18] D. Mathis and C. Benoist, "Aire," Annual Review of Immunology, vol. 27, pp. 287-312, 2009.

[19] M. Guerau-de-Arellano, D. Mathis, and C. Benoist, "Transcriptional impact of Aire varies with cell type," Proceedings of the National Academy of Sciences of the United States of America, vol. 105, no. 37, pp. 14011-14016, 2008.

[20] D. Lomada, B. Lin, L. Coghlan, Y. Hu, and E. R. Richie, "Thymus medulla formation and central tolerance are restored in IKK $\alpha^{-/-}$mice that express an IKK $\alpha$ transgene in keratin $5^{+}$ thymic epithelial cells," Journal of Immunology, vol. 178, no. 2, pp. 829-837, 2007.

[21] J. Derbinski, A. Schulte, B. Kyewski, and L. Klein, "Promiscuous gene expression in medullary thymic epithelial cells mirrors the peripheral self," Nature Immunology, vol. 2, no. 11, pp. 1032-1039, 2001.

[22] B. Kyewski and J. Derbinski, "Self-representation in the thymus: an extended view," Nature Reviews Immunology, vol. 4, no. 9, pp. 688-698, 2004.

[23] J. Abramson, M. Giraud, C. Benoist, and D. Mathis, "Aire's partners in the molecular control of immunological tolerance," Cell, vol. 140, no. 1, pp. 123-135, 2010.

[24] G. Musco and P. Peterson, "PHD finger of autoimmune regulator: an epigenetic link between the histone modifications and tissue-specific antigen expression in thymus," Epigenetics, vol. 3 , no. 6, pp. 310-314, 2008.

[25] Q. Ge and W. F. Chen, "Phenotypic identification of the subgroups of murine T-cell receptor $\alpha \beta^{+} \mathrm{CD} 4^{+} \mathrm{CD} 8$ - thymocytes and its implication in the late stage of thymocyte development," Immunology, vol. 97, no. 4, pp. 665-671, 1999.

[26] T. Tian, J. Zhang, L. Gao, X. P. Qian, and W.-F. Chen, "Heterogeneity within medullary-type $\mathrm{TCR} \alpha \beta^{+} \mathrm{CD} 3^{+} \mathrm{CD} 4-\mathrm{CD} 8^{+}$thymocytes in normal mouse thymus," International Immunology, vol. 13, no. 3, pp. 313-320, 2001.

[27] Q. Ge and W.-F. Chen, "Effect of murine thymic epithelial cell line (MTEC1) on the functional expression of $\mathrm{CD} 4^{+} \mathrm{CD} 8$ thymocyte subgroups," International Immunology, vol. 12, no. 8, pp. 1127-1133, 2000.

[28] V. Mallet, A. Blaschitz, L. Crisa et al., "HLA-G in the human thymus: a subpopulation of medullary epithelial but not $\mathrm{CD} 3^{+}$ dendritic cells expresses HLA-G as a membrane-bound and soluble protein," International Immunology, vol. 11, no. 6, pp. 889-898, 1999.
[29] J. Sprent, E.-K. Gao, and S. R. Webb, “T cell reactivity to MHC molecules: immunity versus tolerance," Science, vol. 248, no. 4961, pp. 1357-1363, 1990.

[30] K. Shortman and L. Wu, "Early T lymphocyte progenitors," Annual Review of Immunology, vol. 14, pp. 29-47, 1996.

[31] R. Sousa Cardoso, D. A. R. Magalhães, A. M. T. Baião et al., "Onset of promiscuous gene expression in murine fetal thymus organ culture," Immunology, vol. 119, no. 3, pp. 369-375, 2006.

[32] M. Guerau-de-Arellano, M. Martinic, C. Benoist, and D. Mathis, "Neonatal tolerance revisited: a perinatal window for Aire control of autoimmunity," Journal of Experimental Medicine, vol. 206, no. 6, pp. 1245-1252, 2009.

[33] R. Rugh, The Mouse. Its Reproduction and Development, Burgess, Minneapolis, Minn, USA, 1968.

[34] P. Poussier, T. Ning, D. Banerjee, and M. Julius, "A unique subset of self-specific intraintestinal T cells maintains gut integrity," Journal of Experimental Medicine, vol. 195, no. 11, pp. 1491-1497, 2002.

[35] S. Lefebvre, F. Adrian, P. Moreau et al., "Modulation of HLAG expression in human thymic and amniotic epithelial cells," Human Immunology, vol. 61, no. 11, pp. 1095-1101, 2000.

[36] Z. Selmani, A. Naji, I. Zidi et al., "Human leukocyte antigenG5 secretion by human mesenchymal stem cells is required to suppress T lymphocyte and natural killer function and to induce $\mathrm{CD} 4{ }^{+} \mathrm{CD} 25$ highFOXP ${ }^{+}$regulatory T cells," Stem Cells, vol. 26, no. 1, pp. 212-222, 2008.

[37] P. Moreau, G. Mouillot, P. Rousseau, C. Marcou, J. Dausset, and E. D. Carosella, "HLA-G gene repression is reversed by demethylation," Proceedings of the National Academy of Sciences of the United States of America, vol. 100, no. 3, pp. 1191-1196, 2003.

[38] J. Boucraut, T. Guillaudeux, M. Alizadeh et al., "HLA-E is the only class I gene that escapes CpG methylation and is transcriptionally active in the trophoblast-derived human cell line JAR," Immunogenetics, vol. 38, no. 2, pp. 117-130, 1993.

[39] T. Ungchusri, E. Y. Chiang, G. Brown et al., "Widespread expression of the nonclassical class I Qa-2 antigens in hemopoietic and nonhemopoietic cells," Immunogenetics, vol. 53, no. 6, pp. 455467, 2001.

[40] I. N. Crispe, “The liver as a lymphoid organ," Annual Review of Immunology, vol. 27, pp. 147-163, 2009.

[41] T. Cupedo, G. Kraal, and R. E. Mebius, "The role of $\mathrm{CD} 45^{+} \mathrm{CD} 4^{+} \mathrm{CD} 3$ - cells in lymphoid organ development," Immunological Reviews, vol. 189, pp. 41-50, 2002.

[42] M. A. Hyatt, H. Budge, and M. E. Symonds, "Early developmental influences on hepatic organogenesis," Organogenesis, vol. 4, no. 3, pp. 170-175, 2008.

[43] C. Götherström, A. West, J. Liden, M. Uzunel, R. Lahesmaa, and K. Le Blanc, "Difference in gene expression between human fetal liver and adult bone marrow mesenchymal stem cells," Haematologica, vol. 90, no. 8, pp. 1017-1026, 2005.

[44] J. C. de Oliveira Crispim, T. G. A. Silva, F. J. D. Souto et al., "Upregulation of soluble and membrane-bound human leukocyte antigen $G$ expression is primarily observed in the milder histopathological stages of chronic hepatitis $\mathrm{C}$ virus infection," Human Immunology, vol. 73, no. 3, pp. 258-262, 2012.

[45] F. J. D. Souto, J. C. O. Crispim, S. C. Ferreira et al., "Liver HLA-G expression is associated with multiple clinical and histopathological forms of chronic hepatitis B virus infection," Journal of Viral Hepatitis, vol. 18, no. 2, pp. 102-105, 2011. 
[46] P. C. Arck, A. Gilhar, J. Bienenstock, and R. Paus, "The alchemy of immune privilege explored from a neuroimmunological perspective," Current Opinion in Pharmacology, vol. 8, no. 4, pp. 480-489, 2008.

[47] S. E. Hiby, A. King, A. Sharkey, and Y. W. Loke, "Molecular studies of trophoblast HLA-G: polymorphism, isoforms, imprinting and expression in preimplantation embryo," Tissue Antigens, vol. 53, no. 1, pp. 1-13, 1999.

[48] M. Ohtsuka, H. Inoko, J. K. Kulski, and S. Yoshimura, "Major histocompatibility complex (Mhc) class Ib gene duplications, organization and expression patterns in mouse strain C57BL/6," BMC Genomics, vol. 9, article 178, 2008.

[49] C. Macedo, C. Moraes Junta, and G. A. S. Passos, "Onset of T-cell receptor $\mathrm{V} \beta 8.1$ and $\mathrm{D} \beta 2.1 \mathrm{~V}(\mathrm{D}) \mathrm{J}$ recombination during thymus development of inbred mouse strains," Immunology Letters, vol. 69, no. 3, pp. 371-373, 1999.

[50] D. A. R. Magalhães, C. Macedo, C. M. Junta et al., "Hybridization signatures during thymus ontogeny reveals modulation of genes coding for T-cell signaling proteins," Molecular Immunology, vol. 42, no. 9, pp. 1043-1048, 2005.

[51] M. Von Köckritz-Blickwede, M. Rohde, S. Oehmcke et al., "Immunological mechanisms underlying the genetic predisposition to severe staphylococcus aureus infection in the mouse model," American Journal of Pathology, vol. 173, no. 6, pp. 16571668, 2008.

[52] X. Sun, H. P. Jones, L. M. Hodge, and J. W. Simecka, "Cytokine and chemokine transcription profile during Mycoplasma pulmonis infection in susceptible and resistant strains of mice: Macrophage inflammatory protein $1 \beta$ (CCL4) and monocyte chemoattractant protein 2 (CCL8) and accumulation of CCR $5^{+}$ Th cells," Infection and Immunity, vol. 74, no. 10, pp. 5943-5954, 2006.

[53] S. D. Cangussú, C. C. de Souza, C. F. Campos, L. Q. Vieira, L. C. C. Afonso, and R. M. E. Arantes, "Histopathology of Leishmania major infection: revisiting L. major histopathology in the ear dermis infection model," Memorias do Instituto Oswaldo Cruz, vol. 104, no. 6, pp. 918-922, 2009.

[54] D. R. Neill, V. E. Fernandes, L. Wisby et al., “T regulatory cells control susceptibility to invasive pneumococcal pneumonia in mice," PLOS Pathogens, vol. 8, no. 4, Article ID e1002660, 2012. 


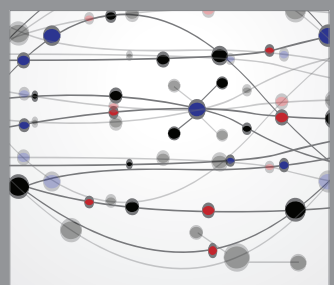

The Scientific World Journal
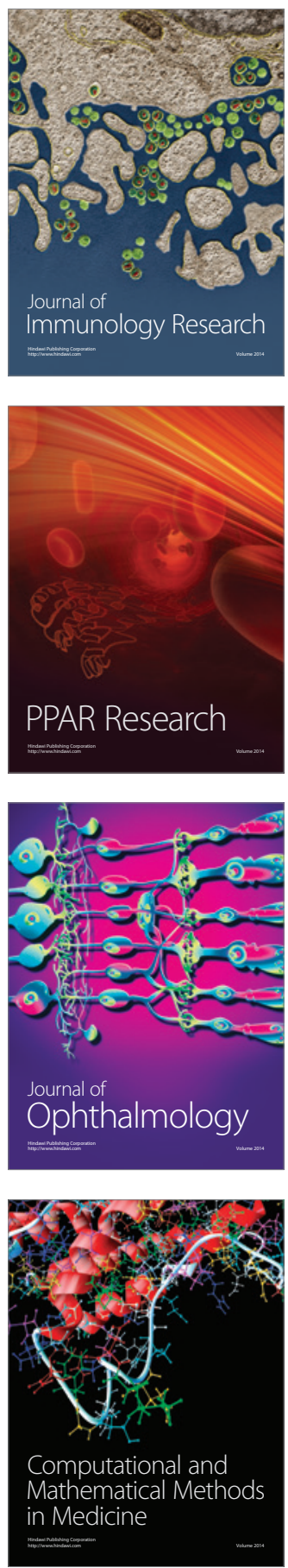

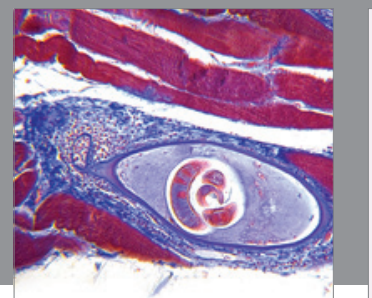

Gastroenterology

Research and Practice
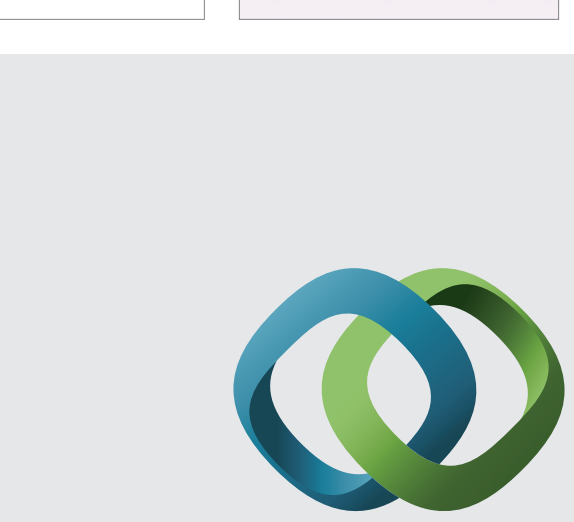

\section{Hindawi}

Submit your manuscripts at

http://www.hindawi.com
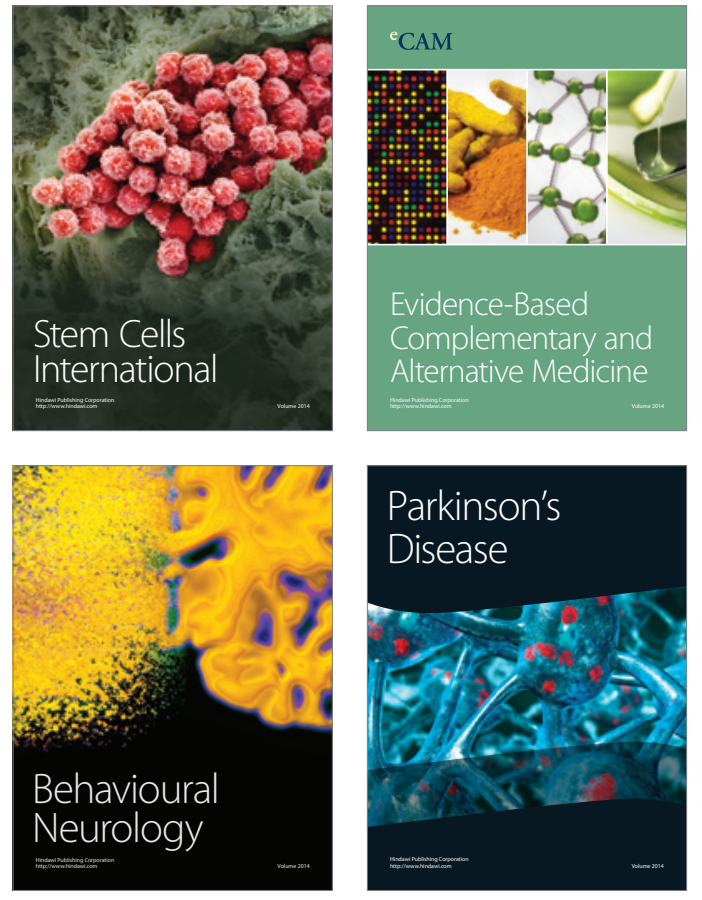
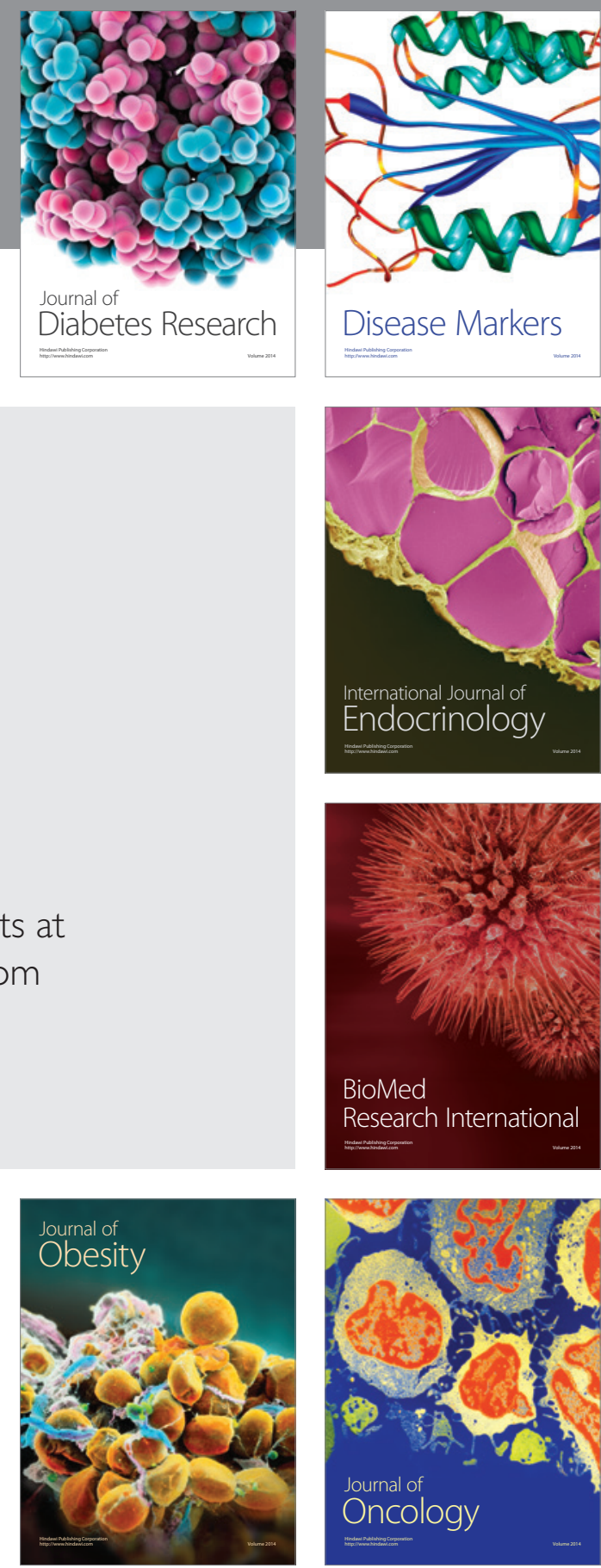

Disease Markers
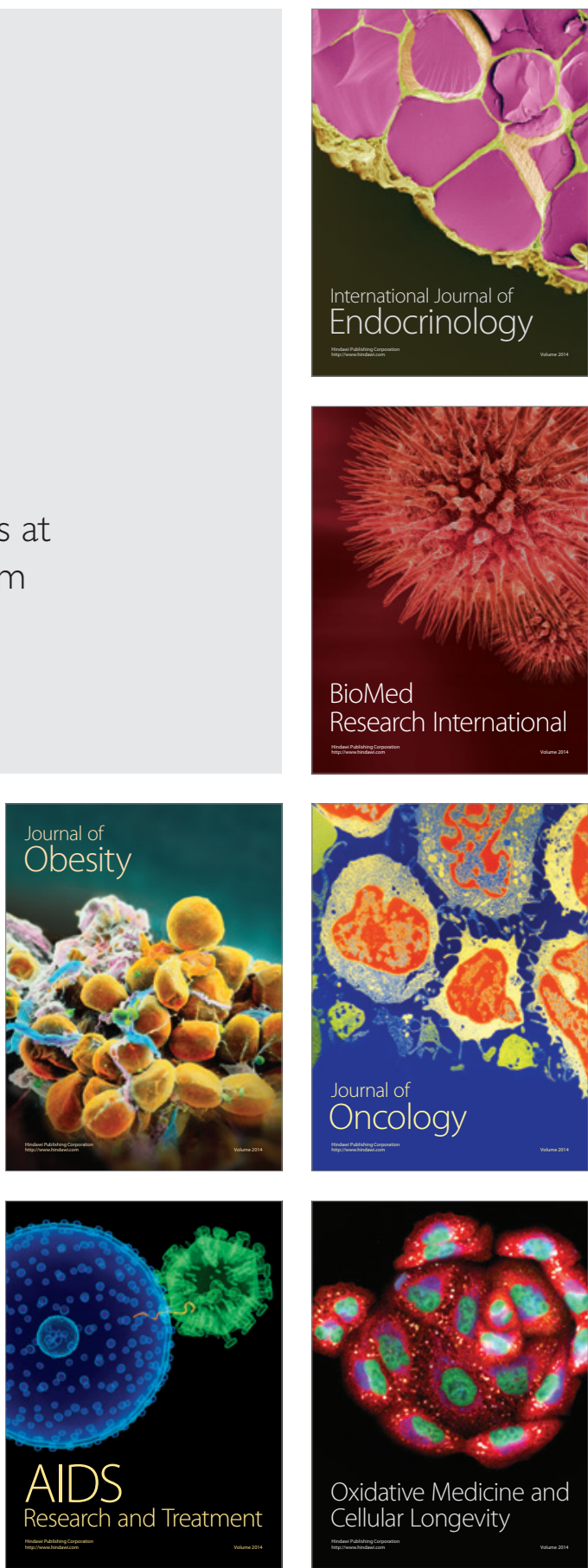